\title{
Lules, isistines y omoampas en el relato histórico de un misionero jesuita en las fronteras del Chaco
}

Lules, Isistines and Omoampas in a historical account written by a Jesuit missionary in the frontiers of the Chaco region

\section{Carina P. Lucaioli and Daniela Sosnowski}

\section{OpenEdition}

\section{Journals}

Electronic version

URL: http://journals.openedition.org/corpusarchivos/2457

DOI: 10.4000/corpusarchivos.2457

ISSN: 1853-8037

\section{Publisher}

Diego Escolar

\section{Electronic reference}

Carina P. Lucaioli y Daniela Sosnowski, «Lules, isistines y omoampas en el relato histórico de un misionero jesuita en las fronteras del Chaco », Corpus [En línea], Vol. 8, No 2 | 2018, Publicado el 03 enero 2019, consultado el 01 mayo 2019. URL : http://journals.openedition.org/corpusarchivos/2457 ; DOI : 10.4000/corpusarchivos.2457

This text was automatically generated on 1 May 2019. 


\section{Lules, isistines y omoampas en el relato históricode un misionero jesuita en las fronteras del Chaco}

Lules, Iisistines and Oomoampas in a historical account written by a Jesuit missionary in the frontiers of the Chaco region

Carina P. Lucaioli and Daniela Sosnowski

\section{EDITOR'S NOTE}

Fecha de recepción del original: 10/09/2018

Fecha de aceptación para publicación: 10/10/2018

1 Las reducciones jesuitas del Chaco han cobrado mayor relevancia en las últimas décadas, volviéndose un campo de investigación particular dentro de los estudios de frontera. En estos enclaves se desplegaron intensas formas de relación entre indígenas, misioneros e hispanocriollos, convirtiéndose en espacios privilegiados para la convivencia, los mestizajes y las adaptaciones socioculturales durante el siglo XVIII. En torno a estos espacios, los misioneros jesuitas alcanzaron un conocimiento muy preciso sobre los grupos indígenas basado tanto en el interés por la cultura general que promovía la Compañía de Jesús como por el trato cotidiano y las relaciones interpersonales que supieron tejer en los ámbitos reduccionales. A su vez, los jesuitas fueron prolíficos productores de documentos escritos; sus relatos son ricos en detalles y bastante confiables en sus datos, lo que los posiciona como una fuente de consulta indispensable para los investigadores de los grupos indígenas del pasado colonial.

El corpus de documentos jesuitas es muy amplio y heterogéneo, aun si limitamos nuestro recorte al espacio chaqueño. Los más conocidos son, quizás, aquellos que conforman el conjunto de relatos escritos por los misioneros luego de la expulsión de la Compañía de Jesús de los dominios españoles en América en 1767. Sin embargo, ellos constituyen 
apenas una pequeña parte de la producción escrita en los diferentes ámbitos de incumbencia de la orden, que abarcaba la administración de los colegios, las estancias y las misiones, la adaptación de las tareas evangélicas y la gestión de conocimiento histórico, lingüístico y cultural, entre otros aspectos. De todos ellos, son los papeles escritos por los misioneros en el ámbito de las reducciones los que brindan mayor cantidad y calidad de datos sobre los grupos indígenas. Nos referimos, por ejemplo, a la correspondencia entre misioneros, o entre ellos y los funcionarios gubernamentales, y a los catálogos o anuas que debían enviar regularmente a los Colegios. Lamentablemente, ellos son también los que más sufrieron los avatares de la conservación. Escritos en y para enclaves alejados de los centros urbanizados y conservados en su mayoría por los propios misioneros en las viviendas o iglesias de las precarias reducciones del Chaco, la enorme mayoría de estos papeles no lograron preservarse luego de la expulsión. Incluso durante la experiencia misional, las condiciones climatológicas extremas, las continuas mudanzas de los pueblos, los incendios y las inundaciones, entre otros factores, contribuyeron a que este sea un corpus particularmente fragmentado e incompleto en comparación con otros documentos producidos por la Compañía de Jesús. Es por ello que los papeles de este tipo que se conservan conforman documentos extremadamente valiosos para la historia indígena. En este artículo hemos decidido transcribir y compartir uno de esos ejemplares. Se trata de un documento que creemos tan excepcional en su tipo como valioso en cuanto a su contenido, ya que preserva un discurso denso --escrito por uno de los misioneros a cargo de la reducción-- que permite reconstruir un momento particular de San Esteban y de las relaciones interétnicas entre los grupos lules, isistines y omoampas y con distintos sectores hispanocriollos en las fronteras del Chaco occidental.

\section{El manuscrito y sus contextos}

3 Proponemos en este apartado una crítica interna del documento. Entendemos que los papeles de archivo constituyen discursos históricamente situados y que en ellos convergen distintos niveles contextuales que contribuyen a su interpretación (Nacuzzi 2002). Sin pretender ser exhaustivas, presentamos algunas consideraciones sobre el contexto de enunciación, el contexto de las situaciones sociales precisas y el contexto de circulación y preservación, que creemos indispensables para interpretar el relato de la Anua histórica y abordar los datos más destacados que se desprenden de su lectura.

El documento que transcribimos, titulado "Anua histórica de la Misión de San Estevan de los Indios Lules de 1744", forma parte de la Colección que Pedro De Angelis vendió a la Biblioteca Nacional de Río de Janeiro (BNRJ, en adelante) y que se encuentra microfilmada para su consulta. Una copia de dichos microfilms fue adquirida por la directora de nuestro equipo de investigación durante una estadía de trabajo de campo en el año 2008. Para este trabajo hemos consultado una versión digitalizada del rollo 33 de dicha colección; específicamente es el último de los documentos reunidos bajo la carátula denominada "36 anuas de las reducciones del Chaco, desde el año de 1744 hasta 1766". Se trata de una copia en blanco y negro, escrita con un trazo bien marcado y letra relativamente clara, por lo que no presenta inconvenientes para la lectura. Sin embargo, reconocemos que la imposibilidad de acceder a los papeles originales dificulta la identificación de detalles como el tipo de papel utilizado, la tinta u otras marcas que se pudieron haber agregado con posterioridad. El documento consta de 5 folios escritos en recto y verso que en la versión digital comprende las páginas 441 a 450 del rollo de 
microfilm. En el margen superior los archiveros han agregado códigos de catalogación, presumiblemente de dos momentos distintos, y cada folio se encuentra sellado con la inscripción "Biblioteca Nacional Rio de Janeiro Secção de Manuscriptos". El texto finaliza abruptamente, sin la presencia de las fórmulas habituales de despedida ni la firma de su autor. Desconocemos los motivos de este final imprevisto, aunque descartamos que se deba a la pérdida posterior de algún folio, ya que el escrito se interrumpe en el segundo renglón de la última hoja, la cual queda casi completamente en blanco. Podría, no obstante, tratarse de una copia incompleta basada en un escrito original que no hemos hallado o de una copia de resguardo hecha por el propio Andreu para su registro personal.

5 En cuanto al contenido, el relato se desenvuelve en torno a diferentes sucesos ocurridos entre los grupos indígenas lules, omoampas e isistines durante un período histórico muy poco estudiado hasta el momento para ese espacio de la frontera chaqueña. Dichos acontecimientos están relacionados con dos tareas que el provincial Bernardo Nusdorffer había encargado a los misioneros de San Esteban en su visita a la reducción a comienzos de 1744. Para informar apropiadamente sobre los resultados de ambas empresas, el autor narra diversos episodios ocurridos en el pasado, lo que permite reconocer y reconstruir la trayectoria de algunos grupos indígenas desde varios años atrás hasta el momento de la redacción del documento. Dicha perspectiva histórica sobre los grupos indígenas le imprime a esta fuente un carácter sin dudas singular. Además del relato histórico, en las últimas páginas se incluyen datos sobre el estado de la reducción hacia fines del año 1744. Una lectura no lineal del relato permite rescatar otro tipo de información más general, pertinente al funcionamiento de las reducciones jesuitas, a las formas de interacción con los grupos indígenas y de estos entre sí, a los modos de hacer de los misioneros frente a los dilemas de la evangelización y a los circuitos administrativos en torno a las visitas de los padres provinciales y los informes de los misioneros a cargo de la reducción. En este sentido, consideramos que esta transcripción puede contribuir tanto para el análisis microhistórico de los grupos lules, omoampas e isistines hacia mediados del siglo XVIII, como aportar al estudio de un contexto más amplio relativo a la conformación de los espacios de frontera en el Chaco austral. El enfoque dependerá, retomando a Revel (2015), del juego de escalas que se proponga privilegiar cada investigador.

6 Para aproximarnos al contexto de enunciación, prestamos atención a los diacríticos ortográficos, gramaticales y caligráficos del texto. El documento posee una letra uniforme, lo que indicaría la participación de un único escribiente y se encuentra escrito en tercera persona. Aunque no está firmado, consideramos que pertenece al jesuita Pedro Juan Andreu. A partir de un trabajo previo que hemos realizado con un corpus más amplio de anuas de la cual este documento forma parte, hemos reconocido que la caligrafía en "Anua histórica de la Misión de San Estevan..." coincide con una anotación firmada por este misionero en su visita a la reducción de Concepción de abipones en 1762, cuando era provincial de la Compañía de Jesús. Reafirmamos esta hipótesis al cotejar la letra de estos dos documentos con otros manuscritos de Andreu. En 1744, él era uno de los dos misioneros a cargo de San Esteban, por lo que conocía de primera mano los datos y episodios volcados en el manuscrito. Concluimos, entonces, que Andreu es el autor del documento que presentamos y que lo habría escrito en el contexto mismo de la reducción que, luego de sufrir sucesivas mudanzas, ese año se situaba provisionalmente en la estancia del Conventillo (Aguilar 2016, Page 2012, Furlong 1941). Un dato curioso para destacar es que el propio Andreu es uno de los actores principales de los sucesos relatados 
en el documento y, aun así, en ningún momento recurre a la primera persona ni realiza una autorreferencia de sus acciones: "Aunque el Padre Andreu se dio la prysa posible no pudo llegar hasta mediado Marzo a los Omoampas" (3v. p. 446), "Saliose el Misionero dexando agasajados, y contentos a los Indios" (3v. p. 446), "solo pudo ver este Misionero [Andreu] dos parcialidades de ella" (4v. p. 448), "Avíalo observado el Padre Pedro Andreu" (3r. p. 445). El uso genérico de la tercera persona puede justificarse por el formato administrativo apropiado para este tipo de informes, pero también como un recurso discursivo que permitía diluir los logros individuales resaltando el carácter divino de la empresa de evangelización jesuita, donde el misionero era concebido como un instrumento de la voluntad de Dios (Vitar 2001a).

7 Con respecto al contexto de las situaciones sociales precisas, el relato se inscribe en una coyuntura específica de las relaciones entre la Corona y la Compañía de Jesús. Sabemos por otros documentos que al poco tiempo de haber asumido el provincial Nusdorffer en 1743, una cédula requería informar al rey de forma detallada sobre los avances de los jesuitas en la evangelización de los indios de toda la provincia del Paraguay. Por otra parte, los padres provinciales asumían con anterioridad la tarea de informar periódicamente a sus superiores acerca de los avances evangélicos por medio de las Cartas Anuas que cada provincia jesuita debía elevar a Roma. De esta manera, debía redactarse un informe anual dirigido a las altas esferas de la Compañía de Jesús pero también a los representantes máximos de la Corona. Podemos suponer, entonces, que este informe consiste en una respuesta de los misioneros a los pedidos del provincial Nusdorffer tanto para poder cumplir con las órdenes del rey como para recabar información pertinente para la mejor administración de las misiones por parte de la Orden y la redacción de las Cartas Anuas. Según el ideal de la formula scribendi, la Compañía de Jesús establecía un cuidadoso control sobre los escritos producidos por los miembros de la Orden, quienes debían atenerse a dos tipos de escritura: la mostrable y la no mostrable o confidencial (Justo 2013, Vega 2017). La confección de las Cartas Anuas requería que desde cada misión se enviase un informe preferentemente numérico -denominado anua o catálogo-- con datos poblacionales y del estado del pueblo y se estipulaba que cualquier otra noticia pertinente se enviara en papel aparte (Maeder 1997). En este sentido, consideramos que el manuscrito que aquí transcribimos --titulado por su autor como "Anua histórica de San Estevan..."--, podría tratarse de un texto subsidiario y complementario del catálogo poblacional correspondiente a ese año de 1744 y que en él se incluyeron esos otros datos que no tenían lugar en dicho catálogo pero que el autor juzgó importante comunicar. Creemos que se trata de un documento excepcional que puede inscribirse dentro de la esfera normativa de la formula scribendi, pero también como producto de la escritura de los márgenes (Wilde 2011), en tanto registra la experiencia subjetiva y particular de un misionero en espacios alejados de los centros de control.

8 Enfocándonos, por último, en el contexto de circulación y preservación, señalamos ya que muy probablemente este manuscrito se haya producido en la reducción de San Esteban. Con los escasos datos de que disponemos, no hemos podido reconstruir la trayectoria del documento desde la reducción hasta su destino original -- ¿el Colegio Máximo de Córdoba?--, ni tampoco el periplo mediante el cual llegó, ya durante el siglo XIX, a manos de Pedro De Angelis, quien lo vendió luego junto con gran cantidad de otros documentos a la BNRJ. Allí fue catalogado y conservado dentro de la copiosa Colección que lleva su nombre y que hemos consultado para su transcripción. 


\section{Una primera aproximación a los datos}

Aun tratándose de un documento relativamente corto en extensión, consideramos que el texto de "Anua Histórica" condensa una gran cantidad de datos valiosos poco habituales de hallar en otro tipo de documentos para el estudio de las dinámicas interétnicas y el proyecto de reducciones jesuitas en las fronteras coloniales. Ante todo, y como su título lo indica, este discurso se refiere a la situación histórica de un grupo de lules reducidos en San Esteban. Es este un aporte en sí mismo, ya que no abunda la información de primera mano sobre la experiencia misional de estos grupos en particular, ni tampoco constituyó una temática estudiada en profundidad por los investigadores. La reducción, llamada en un primer momento San Esteban de Balbuena (1711) y, años más tarde, San Esteban de Miraflores (1715) --según los sitios en los que estuvo emplazada--, fue la primera fundada en la gobernación del Tucumán, como resultado de la entrada realizada por Esteban de Urízar y Arespacochaga y las negociaciones entabladas con los lules y otros grupos indígenas de la región (Vitar 1997, Aguilar 2016). Como veremos a continuación, la información de esta anua no se restringe a los grupos lules, iluminando muchos otros aspectos propios de la coyuntura de la frontera del Chaco occidental y de las políticas de control colonial sobre los grupos indígenas insumisos hacia mediados del siglo XVIII. Lejos de realizar un análisis exhaustivo del contenido del documento, nos hemos propuesto, en este apartado, deslindar algunas de las principales problemáticas a las que aportan los datos incluidos en el relato.

10 Como señalamos anteriormente, este documento fue escrito desde la misión de San Esteban por el padre Andreu y estuvo probablemente dirigido a las autoridades de la Compañía de Jesús con sede en el Colegio Máximo de Córdoba. El objetivo aparente consistía en informar a sus superiores no solo sobre el estado actual de la misión sino también sobre el resultado de dos tareas específicas asignadas por el provincial en su visita anual. Una de ellas consistía en atraer nuevamente a la reducción a un grupo de lules que se había revelado y se encontraba radicado en el Palomar y, la otra, en realizar una nueva entrada a la tierra adentro del Chaco para reducir a grupos omoampas e isistines libres. Para abordar estos temas principales, el autor del documento brinda datos sobre muchas otras cuestiones que constituyen indicios muy interesantes para el estudio de la historia indígena del período colonial.

11 Una primera observación que podemos realizar en torno a los datos del manuscrito es sobre el registro de rótulos étnicos correspondientes a distintos grupos indígenas que interactuaban entre sí en la frontera occidental del Chaco. Se menciona a los lules, los isistines, los omoampas y, secundariamente, a los tobas. Como ya ha sido señalado por varios colegas, la identificación de los grupos étnicos es un paso ineludible para el estudio e interpretación de la historia colonial y constituye una problemática en sí misma, tanto por las dificultades para su comprensión y las imprecisiones de su registro en el pasado, como por las dinámicas propias de la identidad y las transformaciones impulsadas por el contacto colonial (Boccara 1998, Nacuzzi 1998, Giudicelli 2010, Calavia Sáez 2013, Nacuzzi y Lucaioli 2017). Sobre los omoampas, por ejemplo, el autor de este documento agrega un dato muy particular aclarando que esta "nación" era "antes conocida por el nombre de Yuanes" (3r. p. 445). De esta manera, introduce un posible cambio en los rótulos étnicos a lo largo del tiempo que podría analizarse desde la perspectiva de las dinámicas de etnogénesis y etnificación. 
12 Además de los grupos indígenas, en el documento se reconoce la actuación de distintos personajes de los sectores religiosos, gubernamentales y civiles de la sociedad hispanocriolla. En cuanto a los actores religiosos, se destaca la acción de los curas misioneros y la función de supervisión y control del padre provincial en la instancia de las visitas a las misiones de frontera. Del ámbito de la administración colonial, en el documento se identifican distintos funcionarios de la región como un gobernador y dos de sus tenientes de las ciudades vecinas y se hace mención de sus diferentes formas de intervención con las reducciones y determinados grupos indígenas. Otro dato que nos resulta interesante es la mención de actores de la sociedad civil que actuaban en los espacios de frontera, como los meleadores, los recolectores de cera y los mercaderes, a quienes se los ubica en estrecho contacto con los grupos indígenas, ya sea reducidos como no reducidos. Continuando con los actores de esta coyuntura, también es posible identificar en este texto diferentes tipos de intermediarios culturales, como los misioneros, los peones ladinos y los exploradores --del sector hispanocriollo-- o, entre los indígenas, el líder lule del Palomar y los "indios amigos" que hacen de baqueanos y guías en las entradas de los misioneros jesuitas al Chaco.

13 En un plano más particular, este documento registra los nombres de varios actores sociales del período colonial. Del sector indígena, solo se identifica con nombre al capitán de indios lules, Miguel Icaco, aunque también se menciona la participación individualizada de un "Cazique" Oomoampa que hablaba quichoa. Del sector jesuita, aparecen mencionados los siguientes padres provinciales que cumplieron sus funciones en períodos sucesivos: Jaime Aguilar --que se desempeñó entre 1733 y 1739--; Sebastián de San Martín --en 1739--; Antonio Machoni --entre 1739-1743-- y Bernardo Nusdorffer, quien ocupó el cargo entre 1743 y 1747 y fue quien motivó la redacción de este informe. Asimismo, se identifican los curas doctrineros de la reducción de San Esteban --los padres Pedro Antonio Artíguez y Pedro Juan Andreu-- y los misioneros Juan de Arizaga, del Colegio de Santiago del Estero y Joaquín de Yegros, del Colegio de La Rioja. Se mencionan también tres funcionarios de la administración colonial: el entonces gobernador del Tucumán, Juan Santiso; el teniente de gobernador de Santiago, Joseph López y Joseph Luis Días, teniente de gobernador de Catamarca y la Rioja.

14 Todos estos sectores, actores y personajes del ámbito fronterizo, aparecen en el relato realizando acciones y estableciendo entre sí diversos vínculos políticos, económicos y sociales. De esta manera, a partir de la lectura del documento es posible delinear diversas formas y combinaciones que adoptaron las relaciones sociales e interétnicas en esta coyuntura en particular, entre indígenas e hispanocriollos y, también, entre diversos grupos indígenas entre sí. En esta anua se habla de grupos reducidos; de conflictos internos en la población de San Esteban; de negociaciones entre indígenas y funcionarios; de relaciones interétnicas de parentesco; de toma de cautivos; de transacciones económicas interétnicas en las fronteras y tierra adentro; de colaboración entre los sectores hispanocriollos y el proyecto jesuita; de la participación de "indios amigos" en las entradas evangelizadoras; de enfrentamientos armados y muertes; y de convivencia interétnica y de fronteras inestables por los grupos insumisos. Todos ellos conforman indicios que nos permiten reconstruir el cuadro de relaciones hacia mediados del siglo XVIII en este pequeño recorte del espacio fronterizo chaqueño. Una primera aproximación a estos datos permite analizar que la perspectiva hispanocriolla y jesuita sobre las relaciones con los grupos indígenas reconocía un grado creciente en los conflictos y enfrentamientos a medida que se avanzaba sobre tierra adentro. De esta 
manera, podría pensarse esta coyuntura en un continuum de menor a mayor conflictividad comenzando con los grupos lules reducidos, siguiendo por los isistines y omoampas -ubicados en las inmediaciones de la frontera occidental y con quienes ya habían tenido negociaciones diplomáticas en el pasado-- $\mathrm{y}$, por último, los tobas insumisos, enemigos radicales de la colonia.

Aunque este esquema sintetiza la percepción de los sectores coloniales sobre las relaciones interétnicas con los grupos indígenas, resulta interesante rescatar la presencia de otros niveles de análisis en el relato. Los grupos étnicos son percibidos como tales pero, también, como grupos de personas con disidencias y matices internos. Para ilustrar este punto, podemos señalar que el autor del documento reconoce dos subgrupos entre los lules con distintas estrategias de relacionamiento con la sociedad colonial; uno que permanecía bajo tutela jesuita en San Esteban y otro que había abandonado la reducción para radicarse en un paraje cercano. Estos últimos, mantenían una relación tensa con los lules reducidos y particularmente con los misioneros a cargo que buscaban reincorporarlos; sin embargo, habían logrado entablar estrechos vínculos de colaboración con el teniente de gobernador de Santiago del Estero y con grupos de meleadores y comerciantes de cera, participando tanto de la defensa de las fronteras frente a posibles incursiones de indígenas insumisos como de las redes de intercambio económico de la región.

El documento también se detiene en las relaciones interétnicas entre los lules y otros grupos indígenas no reducidos. Se desprende del texto que la relación con los isistines era amigable y estrecha, incluso atravesada por vínculos de parentesco, lo que permitía la convivencia de individuos de ambos grupos en la reducción. Por el contrario, se mencionan enfrentamientos, acciones armadas y tomas de cautivos entre lules y omoampas, aún durante la experiencia jesuita. Las tensiones entre ambos grupos hacían inviable la posibilidad de incorporar a los omoampas a San Esteban, es por ello que los jesuitas encararon, aunque sin éxito, la fundación de una nueva reducción para este grupo como corolario de las arduas negociaciones para evangelizarlos. Además, el registro de Andreu provee indicios de las malas relaciones entre los omoampas y los tobas, quienes no solo habrían destruido los avances de la nueva reducción sino que habrían matado a ocho de sus principales referentes. El cruce de este documento con muchos otros producidos para este espacio, permite señalar a los tobas, abipones y mocovíes como los principales "enemigos" de la colonia y, quizás, situar dentro de esta misma trama de conflictos este episodio contra los omoampas y su futura reducción. Pueden realizarse otras lecturas más detalladas y precisas de las relaciones sociales e interétnicas delineadas en este relato, no obstante, creemos que alcanza este recorrido para dar cuenta de la riqueza del discurso sobre este tipo de datos esquivos en otras fuentes contemporáneas, cuya particularidad descansa en el conocimiento específico que adquirieron los jesuitas misioneros sobre los grupos indígenas no sometidos a su control.

El estudio de las relaciones interétnicas se entreteje con el de las instituciones de frontera fomentadas por la administración colonial frente a los grupos indígenas insumisos. Este documento aporta información relevante sobre las reducciones y los fuertes, en primer lugar y, de manera secundaria, sobre el comercio interétnico y la diplomacia. Asimismo, pone en relieve ciertas dinámicas de retroalimentación y solapamiento entre estas modalidades de contacto. Escrito desde el ámbito de las reducciones, brinda detalles muy precisos y específicos acerca de la puesta en práctica del proyecto de fundar misiones para los grupos insumisos del Chaco y sus diversas etapas: las negociaciones con los 
grupos de tierra adentro --ilustrado con los episodios que el autor define como "la tragedia de los Omoampas" (3r. p. 445)--; las vicisitudes y personajes involucrados en la fundación --por ejemplo, la creación de la nueva reducción en el paraje de La Petaca--; las dificultades en la administración del pueblo y en las tareas de evangelización -visible en el relato sobre el estado de la reducción de San Esteban--; la inestabilidad de la población y de los propios emplazamientos forzados a mudanzas sucesivas. Este documento da cuenta, también, del aparato administrativo y la burocracia jesuita en torno a las reducciones, observable en el sistema de visitas por parte de los padres provinciales y en los informes anuales que los misioneros elevaban a sus superiores en cuyo circuito se inserta este informe en particular.

18 Asimismo, este documento brinda un dato muy curioso acerca los fuertes defensivos apostados en las fronteras para contener las presiones de los grupos indígenas insumisos de tierra adentro. El emplazamiento de estos enclaves fue una de las estrategias más habituales implementadas por las ciudades emplazadas en los márgenes del espacio ocupado por los grupos indígenas. Por lo general, se trataba de construcciones precarias y mal abastecidas, guarnecidas por unos pocos soldados que tenían por función contener el avance indígena sirviendo como antemural a las ciudades (Vitar 1988 y 1997). Sin embargo, este relato pone en evidencia un recorrido diferente para la pretendida fundación de uno de estos fuertes. Según Andreu, el líder de los lules, Icaco --radicado en el paraje del Palomar--, le habría sugerido al teniente de gobernador de Santiago del Estero que defendería con su gente la frontera si fundase un fuerte en ese sitio y lo proveyera de carne. Si bien no hay certezas de que se haya instalado el pretendido fuerte, los lules bajo el mando de Icaco se instalaron en el Palomar, cumpliendo las funciones -intencionales o no-- de servir como colchón defensivo frente a las incursiones de otros grupos indígenas. Este episodio da cuenta, también, del conocimiento que tenían los líderes indígenas sobre las instituciones coloniales de los espacios de frontera y del amplio margen de maniobra para elaborar diferentes estrategias de relacionamiento con los sectores hispanocriollos.

19 Además, el manuscrito que aquí transcribimos ilumina otro aspecto reconocido y aceptado por los investigadores pero poco documentado en los relatos escritos que se conservan de la época colonial: el de los intercambios económicos entre los grupos indígenas y diversos actores hispanocriollos en los espacios de frontera y la tierra adentro. Palermo (2000) ha puesto en evidencia la presencia de extensas redes de intercambio entre indígenas e hispanocriollos por las que circulaban diversos tipos de ganados, recursos y productos manufacturados. Un primer indicio de este tipo de transacciones aparece en relación al paraje del Palomar ocupado por Icaco y sus seguidores, el cual es descripto por el autor como "una feria de meleadores y mercaderes de cera" (1v. p. 442), cuyos habitantes no indígenas se dispersaron por los montes mientras duró la visita del misionero para continuar luego con las actividades de extracción en la región. Si bien no se explicitan relaciones de intercambio, entendemos a este sitio como un nodo territorial, ya que constituía un ámbito de encuentro entre indígenas y criollos propiciado por la disponibilidad de determinados recursos --en este caso la miel y la cera-- que fomentaba determinadas actividades económicas. El relato vuelve sobre estas mismas actividades pero en otro contexto: un mercader de cera del Tucumán le anunciaba a los padres doctrineros de San Esteban que tenía trato continuo y pacífico con los omoampas libres, de quienes destacaba su "fidelidad, y legalidad en sus tratos" (3r. p. 445), sentando precedente de los intercambios tierra adentro. Más adelante, 
aparece un nuevo indicio, cuando se señala que los recolectores de cera --“cereadores" en el texto-- "jusgavan ruina de sus ganancias la conversión de los Omoampas" (4r. p. 447), dando a entender que los omoampas participaban activamente en las redes económicas coloniales.

Por último, siguiendo con los datos acerca de las instituciones para la colonización de las fronteras y el control de los grupos indígenas, este documento esboza tangencialmente la dinámica de las negociaciones diplomáticas con los grupos insumisos, aunque circunscripta a la esfera jesuita. La fundación de cada nueva reducción implicaba que previamente se hubieran llevado a cabo una serie de negociaciones en las cuales algunos caciques indígenas aceptaran voluntariamente - -y por motivos muy diversos-radicarse en una misión al cuidado de los padres jesuitas (Lucaioli 2011). Estas tratativas, aun cuando no mediara entre ellas la firma de acuerdos de paz con registro escrito, pertenecían a la esfera de la diplomacia interétnica en donde cada grupo en cuestión definía y negociaba las condiciones de una convivencia pacífica. Gran parte del relato que estamos analizando apunta a informar acerca de las dificultades que enfrentaron los misioneros para sostener y concretar los diálogos con los grupos indígenas en diversos contextos. La detallada "digresión" que realiza el autor sobre las sucesivas instancias de diálogo con los omoampas para acordar la fundación de una nueva reducción, da cuenta de las dificultades implícitas en este proceso; dificultades que involucran problemas de comunicación, desacuerdos, intromisiones de terceros, falta de medios materiales, condiciones climáticas y otra larga serie de variables. Si bien no se detiene en registrar los momentos en que se realizan los acuerdos, pueden reconstruirse ciertos detalles de la dinámica diplomática y algunos de los aspectos discutidos y acordados. Nacuzzi y Lucaioli (2008) señalaron que los procesos de diálogo entre funcionarios e indígenas comenzaban, muchas veces, por una entrada a tierra adentro cuyas tropas iban munidas tanto de armas como de obsequios; así, podía desembocar en un enfrentamiento o, en el mejor de los casos, en el establecimiento de un acuerdo de paz. Las entradas realizadas por los misioneros, aun cuando iban acompañados de indígenas amigos armados, no contemplaban a priori involucrarse en conflictos bélicos sino entablar los diálogos que permitieran comenzar las tareas de evangelización. El caso de los omoampas ilustra muy bien este proceso de avances y retrocesos, donde los jesuitas aplicaron una a una todas la estrategias posibles para lograr atraer a los indígenas insumisos a las reducciones: "con agasajos, con dádivas, con razones, con promesas, y amenazas del castigo" (2v. p. 444). Da cuenta de los desencuentros propios de la negociación, por las falencias del sistema de comunicación mediante señales de humo o por las ausencias indígenas a las citas convenidas. Otros indicios que rastreamos sobre las relaciones diplomáticas indican la preferencia que tenían los grupos indígenas para negociar con unos misioneros antes que con otros --el padre Joaquín de Yegros, en este caso---, lo cual refuerza la hipótesis de la importancia que tenían las relaciones interpersonales entre sujetos específicos para la consecución y puesta en marcha de los proyectos de colonización y control de los grupos insumisos. Entre los aspectos discutidos en los acuerdos de convivencia, el más reiterado y controvertido fue el del lugar en donde se instalaría la reducción; los grupos omoampas tenían sus preferencias --cambiantes a lo largo de los años-- a las que los jesuitas debieron adaptarse una y otra vez sin éxito hasta el momento de la producción de este documento. Estas dilaciones generaban incertidumbre entre los jesuitas que, de todos modos, mantenían la esperanza de fundar nuevas reducciones basándose en la presunción de buena voluntad por parte de los grupos indígenas. De esta manera, llegar a concretar una fundación podía requerir de muchos esfuerzos e implicar largos períodos de tiempo 
ritmados por encuentros fortuitos, futuras promesas y el establecimiento de nuevas condiciones. Por otra parte, el texto alude al carácter lábil de los diálogos, que se hace evidente tanto en las dificultades por renovar las alianzas con los grupos omoampas como en las fluctuaciones de la población lule de San Esteban, cuya resolución no estaba al alcance de los padres misioneros. Las causas de esta fragilidad pueden rastrearse tanto en la falta de incentivos del proyecto jesuita, como en las voluntades indígenas que buscaban mejorar sus condiciones por medio de otras estrategias de interacción, pero, además, en la incapacidad de los sectores coloniales de controlar esas migraciones.

21 Este documento se destaca por la riqueza de su información etnográfica sobre los grupos indígenas. Aquí solo vamos a identificar algunos ejes de análisis cuyo estudio contribuiría a avanzar en el conocimiento sobre los grupos étnicos durante el período colonial. El relato de Andreu pretende, entre otras cosas, informar acerca del estado de la reducción de San Esteban y de la situación de los grupos lules reducidos. Desde esta óptica, el misionero brinda valiosos indicios acerca de las transformaciones sociopolíticas y culturales de los grupos indígenas en los contextos de reducción. Casi al comienzo del relato, por ejemplo, se registra que el líder que se había asentado en el Palomar era "Miguel Icaco, Indio de esta Reducción a quien, en visita de ella, dio el bastón de Capitán el Señor Gobernador Don Juan Santiso" (1r. p. 441). Como bien han analizado varios investigadores, la entrega de este tipo de distinciones por parte de los funcionarios hispanocriollos tenía por objetivo la creación de líderes indígenas que actuaran como representantes de sus grupos a partir del otorgamiento de un poder político no necesariamente legítimo ni surgido por las vías tradicionales del cacicazgo (Vitar 1997 y 2003, Nacuzzi 1998, Roulet 1999-2001, Saeger 2000, Paz 2005 y Lucaioli 2011). De esta manera, con fines administrativos se buscaba intervenir en la estructura política de los grupos indígenas amigos o reducidos para facilitar su control; sin embargo, además de los conflictos políticos que este sistema produjo dentro de los grupos, la respuesta indígena no siempre se condujo por los caminos esperados. La situación de Icaco podría reflejar uno de esos casos. En el documento se señalan dos posibles motivos por los que Icaco habría decidido abandonar la reducción, uno que apunta a cambios en su conducta y personalidad --"ensoberbecido con el empleo" (1r. p. 441) -- y otro, a disputas personales "por disgustos que tuvo con otro Indio Capitán" (1r. p. 441); ambos directamente derivados por del hecho de haber recibido el bastón de mando. Quizás fue gracias a esa distinción que logró entablar vínculos interpersonales con el teniente de gobernador de Santiago del Estero y consiguió el visto bueno para instalarse en el Palomar, desde donde sedujo a los lules reducidos a que se unieran a su grupo. Con estas acciones --y por no querer regresar a San Esteban--, se ganó Icaco la prisión y la pérdida de su bastón, aunque los jesuitas se lo restituyeron una vez reintegrado a la reducción para reafirmar su figura de autoridad y para que pudiese ser enviado nuevamente al Palomar a buscar parte de su gente. Estos episodios merecen un análisis detenido que contemple la complementación de estos datos con otras fuentes del período; sin embargo, creemos que ilustran por sí mismos la complejidad de las transformaciones políticas operadas entre los grupos indígenas en el entrecruzamiento de las autoridades nativas, las hispanocriollas y las religiosas en las que buscaba asentarse la administración colonial.

El texto que transcribimos nos habla de diversas estrategias sociales desplegadas por los grupos indígenas reducidos en la coyuntura colonial. Reconocemos algunos indicios acerca de la adaptación de la libre movilidad y la fluctuación de la población por medio de 
mecanismos de fisión y fusión trasladada ahora a los enclaves fronterizos. Los misioneros, de hecho, dejan entrever su preocupación por las dinámicas de movilidad entre diversos parajes de la frontera como San Esteban --situada en ese momento en el Conventillo--, el Palomar o la Petaca y por la ineficacia de sus métodos de persuasión para mantener la población estable y quieta en la reducción. Como señala Andreu, los motivos por los cuales los lules se alejaban incluían a quien quisiera "huirse con mugeres hurtadas" o a "quantos temían por sus maldades el castigo, o quedavan descontentos, porque se las avía corregido" (1v. p. 442). Se menciona al pasar que los indígenas reducidos continuaban con sus incursiones tierra adentro --"en las últimas refriegas que tuvieron, cogieron varias piezas Omoampas, y se las traxeron a la Reducción" (3r. p. 445)--, reafirmando tanto los enfrentamientos como las alianzas interétnicas. Dentro de esta dinámica se incluye la circulación de cautivos que, una vez en la reducción, podían pasar a formar parte de la población por medio de las alianzas matrimoniales interétnicas, como sucedió con los omoampas llevados por los lules a San Esteban. Estas alianzas y el dato de que los isistines podían convivir en la misma reducción "con los Lules sus parientes" (1r. p. 441) aportarían a la perspectiva de los mestizajes biológicos y culturales operados en las fronteras.

El relato ilumina otros aspectos --algunos de ellos muy poco documentados-- de las transformaciones sociales de los grupos lules impulsadas por la intervención de los jesuitas y su proyecto evangelizador. Por ejemplo, como es habitual en este tipo de informes, se registran los avances en la concurrencia de los indígenas a la misa cantada y al sacramento de la comunión; lo que no es tan habitual, es que se incluya el episodio de un intento de infanticidio en un nacimiento gemelar ocurrido en la reducción. Nos interesa señalar que el relato permite identificar diferentes actitudes frente a este hecho: la de la madre que elige deshacerse de uno de sus hijos recién nacido continuando las tradiciones culturales de su grupo; la de las mujeres más antiguas de la reducción que "afeaban a la parida el hurto de la otra, y decían que aquel era un gran pecado" (5r. p. 449); y la de los misioneros que resolvieron salvar a la criatura condenada bautizándolas a ambas. El infanticidio, era considerado uno de los signos más evidentes de la pretendida barbarie y conducta salvaje de los grupos indígenas que la evangelización buscaba eliminar, al igual que el aborto y el canibalismo, (Vitar 1999). Hasta tal punto se asociaba la erradicación de estas costumbres con el éxito de la conversión, que muy rara vez los misioneros estaban dispuestos a reconocer y dejar por escrito que esas costumbres aún tenían lugar en las reducciones que ellos tenían a cargo.

Entre los datos etnográficos interesantes y poco comunes que brinda este documento, se alude a ciertas costumbres y formas de proceder de los grupos insumisos de tierra adentro. Andreu relata, por ejemplo, que cuando se acercaron a dialogar con los omoampas, "respondió por todos el Cazique en lengua quichoa" (3r. p. 445) si bien no precisa sobre la participación de lenguaraces; habla del uso del sistema de señales de humo para comunicarse con otros grupos alejados en el espacio y de la buena predisposición de los omoampas para recibir regalos y baratijas de los misioneros que buscaban establecer contactos con ellos, lo cual alimentaba la inclusión de elementos exógenos a su cultura material. Otro dato etnográfico singular reside en entender el fracaso de los intentos de reducción de los omoampas por "la innata tenacidad de las mugeres viejas en mantenerse en su paíz nativo" (4v. p. 448). Consideramos que esta mal comprendida "innata tenacidad" podría constituir una alusión velada acerca del poder político de las mujeres ancianas de las comunidades indígenas del Chaco, aspecto que ha 
sido destacado por varios investigadores (Saeger 2000, Vitar 2001b y 2015, Citro 2009, Scala 2015).

Este documento brinda algunos indicios acerca de los usos del territorio por parte de estos grupos indígenas; por ejemplo, la referencia a los pozos de agua --como los de Macolí y Socolí-- como mojones y espacios de encuentro interétnico, que podrían pensarse en términos de nodos territoriales estratégicos (Enrique 2018). Este dato aportaría a la hipótesis de Faberman y Taboada (2017) de que los pozos no solo proveían un recurso escaso y sustancial sino que contribuyeron a organizar la distribución espacial y la movilidad de los grupos indígenas en la tierra adentro. Con motivo de las negociaciones para la reducción de los omoampas, Andreu menciona que en cierta ocasión debió abandonar el proyecto de dar inicio a una sementera de maíz en las inmediaciones de Socolí, porque los indígenas le informaron que "avían desamparado ese parage, y no querían bolver más a él", lo que podría comprenderse desde la perspectiva de la movilidad territorial y el traslado de los asentamientos luego de un determinado período de tiempo, tal como lo señala Noli (1998) para los grupos indígenas prehispánicos del Tucumán.

Finalmente, rescatamos de este documento la información topográfica, datos concretos que describen e identifican parajes, enclaves y nodos en el territorio extenso de la frontera del Chaco occidental. El relato se sitúa, como hemos dicho, en la reducción de San Esteban de indios lules, desde donde partieron los misioneros en sus excursiones para la conversión de los indígenas insumisos hacia los territorios de tierra adentro. Este recorrido es descripto por Andreu como un "camino larguísimo, y penosysimo por los montes y atravesías" (3r. p. 445), que se hacía intransitable por "el rigor del ivierno" (3v. p. 446) y que demoraba los encuentros con los indígenas. La mirada de los misioneros sobre la tierra adentro resalta las ideas de una vegetación poco transitable, de la escasez de recursos --el agua fundamentalmente-- y del peligro por la cercanía de grupos indígenas enemigos. En cuanto a los diacríticos que permiten situar el relato en el espacio, se nombran los parajes del Palomar, la Petaca, la Puerta, el Potrero de las Minas y la Pampa de Don Juan; también se registra el camino de Matará y el Pueblo de Guazán en el Valle de Andargalá; por último, se mencionan las ciudades de Tucumán, Santiago del Estero y Córdoba. Sobre los recursos disponibles tierra adentro se destacan los pozos de agua de Macolí y de Socolí, además del río Salado como el curso hídrico de referencia en este espacio en particular. Estos nombres contribuyen a completar los mapas que los investigadores construimos para situar nuestros estudios en el espacio y a ampliar el conocimiento acerca de las representaciones coloniales del territorio y el paisaje.

Hasta aquí hemos identificado, mediante una lectura transversal del relato, algunas problemáticas posibles de abordar a partir de los datos de este documento, comprendiendo que no agota ni refleja todo su potencial. Entendemos que cada uno de estos ejes solo pueden reconocerse en términos analíticos; en el plano de las acciones sociales y de la coyuntura histórica que buscamos reconstruir a partir de este discurso. Los aspectos étnicos, sociales, políticos y económicos se intersectan, retroalimentan y transforman por medio de la interacción entre grupos étnicos, sectores sociales y actores particulares únicos y diversos. El recorrido que hemos propuesto no busca, tampoco, alimentar la ficción de que este documento se basta a sí mismo. Como cualquier fuente histórica, su riqueza se vislumbra y potencia mediante el cruce y la complementación con otros papeles, con otros discursos y considerando otras miradas sobre los acontecimientos, así como por las nuevas preguntas de investigación y la redefinición de 
las herramientas conceptuales con que los investigadores abordamos el estudio de la historia indígena del pasado colonial.

\section{Criterios para la transcripción del documento}

Para publicar el documento "Anua histórica de la Misión de San Estevan de los Indios Lules de 1744", optamos por presentar una transcripción literal modernizada, siguiendo parcialmente los criterios propuestos por Tanodi (2000). En líneas generales, decidimos respetar la ortografía original del documento, ya que de este modo se posibilita no solo un análisis del contenido del escrito sino también de sus rasgos diplomáticos internos y de la forma de escritura a mediados del siglo XVIII. Confiamos en que las posibles dificultades de lectura serán menores y no imposibilitarán la comprensión del sentido del texto. Se conservaron todas las mayúsculas para respetar especialmente los casos de los rótulos étnicos (Indios Lules), los cargos políticos y eclesiásticos (Padre Provincial) y las instituciones coloniales (Fuerte), ya que es así como están escritas en la mayor parte de los documentos del período. Consideramos que esos pequeños detalles son indicios que nos acercan al momento de la redacción del manuscrito y a las intenciones de su autor.

Sin embargo, juzgamos preciso realizar ciertas modificaciones para que la lectura del documento no resulte por demás engorrosa y para eliminar posibles ambigüedades de sentido. En primer lugar, se desplegaron todas las abreviaturas, las consonantes dobles innecesarias se redujeron a sencillas y la acentuación se actualizó en todos los casos donde correspondía. Las mayores modificaciones se aplicaron a los signos de puntuación. En este caso, los criterios que adoptamos fueron: eliminar el exceso de comas que entorpecían la lectura lineal del relato, mantenerlas siempre y cuando no impusieran dificultades en la comprensión y agregar algunas en aquellas oraciones en las que consideramos indispensable su presencia para la comprensión textual. Además, los signos de punto y coma y los dos puntos fueron eliminados en algunos casos y en otros reemplazados por comas, según correspondiese. Decidimos respetar todas las comas anteriores a las conjunciones "y" y "o", ya que eran muy habituales en el lenguaje escrito de la época y no acarrean problemas de interpretación.

Decidimos hacer explícitas las tachaduras y las acotaciones agregadas entre líneas. Hemos señalado las palabras de difícil comprensión, que si bien no abundan en el texto, forman parte de las características propias del manuscrito original. De esta manera, restituimos entre corchetes las palabras o partes de ellas en los casos en que, por la presencia de manchas de tinta o mala conservación del papel, pudimos inferir la grafía pero sin asegurarlo con certeza. Para palabras mal escritas o "corrompidas" (Tanodi 2000, p. 266), pero claramente legibles, agregamos [sic]. Las palabras tachadas y las inserciones entre líneas fueron marcadas en nota a pie de página. Por último, consideramos importante transcribir tanto la foliación original del manuscrito, con recto y vuelto -- del 1 al 5--, como también la paginación impuesta por la digitalización de los rollos de microfilm -páginas 441 a $450--$.

\section{Documento}

31 Jhs.

32 Anua histórica de la Misión de San Estevan de los Indios Lules de 1744 

Provincial Bernardo Nusdorfer dexó ordenado que el Padre Pedro Antonio Artiguez, uno de los dos Doctrineros de esta Misión, pasara al Palomar para deshacer una gavilla de Indios Lules que allí avía, y re[dirigir]los a su Reducción. Y que después de Pascua de Resurrección fuese el otro Doctrinero el Padre Pedro Juan Andreu acompañado del Padre Juan de Arizaga, que vendría del Colegio de Santiago, a las tierras de los Isistines y Omoampas para solicitar la salida a las cercanías del Tucumán de unos, y otros; para que aquellos se agregasen a esta Reducción con los Lules sus parientes, y estos hiciesen Pueblo aparte en competente distancia del de los Lules para poder ser socorridos de estos, y ser doctrinados separadamente, lexos de sus malos exemplos, y cerca de sus sementeras. acompañado de 20 Lules bien armados, y dos mozos ladinos con bocas de fuego. La empresa era ardua, y avía dado materia a bastantes consultas. El caso pedía remedio, pero apenas se podía hallar medio para remediar el caso. Sin violencia no avía esperanza de conseguir el fin, pero en executar esa violencia se premeditavan gravísimos inconvenientes. El daño consistía en que Miguel Icaco, Indio de esta Reducción a quien en visita de ella dio el bastón de Capitán el Señor Gobernador Don Juan Santiso, ensoberbecido con el empleo, y por disgustos que tuvo con otro Indio Capitán, hizo fuga ahora cuatro años de esta Reducción llevándose consigo cosa de cuarenta almas que pudo pervertir, aviendo intentado pervertir y llevarse todo el Pueblo.

Reducción se fue a Santiago, y propuso al Teniente de Gobernador Don Joseph López que si quería ayudarle en hacer un Fuerte en el Palomar// lomar [sic], y concurrir con darle carne para subsistir en aquella frontera, él juntaría allí toda su Nación, y corriendo el campo con su gente, aseguraría la quietud de estas ciudades fronterizas, estando al reparo de ellas. Esta proposición no fue totalmente despreciada del Teniente, y aunque no se le dieron a Icaco las ayudas de costa que pedía, le despidieron con esperanza para que se mantuviese en aquella frontera por lo bien que le estava a la jurisdicción de Santiago tener ese resguardo en la parte más peligrosa, y amenazada del enemigo.

36 Con ese negociado volvió Icaco contento a los suyos, y dando ya por hecho lo que esperava alcanzar, embió recado a los Indios de la Reducción que ya podían ir todos al Palomar, donde lo pasarían mejor que en la Reducción por los partidos ventajosos que le tenía ofrecidos el Teniente de Santiago. Con esa y semejantes astucias en que gastó ese Ministro de Satanás todo el caudal de su maliciosa sagacidad, que no es poca para despoblar esta Reducción, no solo no pudo contrastarlos indios de esta Reducción pero ni aun pudo mantener consigo a todos los que avía llevado, pues muchos de ellos se bolvieron a la Reducción. Sin embargo era muy perniciosa para esta Cristiandad esa gavilla de Indios porque era un señuelo diabólico donde se agregavan todos los malcontentos de esta Reducción. Ahí hallavan acogida quantos querían huirse con mugeres hurtadas. Ahí se guarecían quantos temían por sus maldades el castigo, o quedavan descontentos porque se las avía corregido.

37 A deshazer pues ese estorvo a los progresos de esta nueva Cristiandad se encaminó el Padre Pedro Artiguez, determinado a traer por bien o por mal a la Reducción a ese Capitán de Indios Apóstatas. Llegó al Palomar escoltado de su gente, y halló aquella estancia hecha una feria de meleadores y mercaderes de cera. Hízolos juntar a todos el Padre Pedro, y les mandó con libertad Apostólica que desocupasen aquel lugar aquella misma tarde, porque tenía que hablar al alma a aquellos sus Lules, y no quería embarazos.

Corpus, Vol. 8, No 2 | 2018 
Algunos salieron del Palomar, otros fingieron que se retiravan, pero previnieron antes a los Lules que solo se escondían en el monte hasta que se bolviese el Padre, que ellos hiciesen lo// mismo, y proseguirían después sus meleadas.

Icaco y sus Indios, que ya estaban hechos a ver Misioneros en sus tierras, que una, y otra vez avían ido a persuadirles la salida, y siempre les avían agasajado, y regalado, nada rezelaron en esta ocasión; antes recibieron al Padre con demonstraciones de alegría, quien correspondió repartiendo a todos el avío que de prevención trahía. El día siguiente les dixo Misa, e hizo una fervorosa plática, y después de ella llamó aparte a Miguel Icaco, y le persuadió la salida con quantas razones de blandura, y amenaza con el castigo de Dios le dictó su Zelo. A todo respondía lo que en otras ocasiones, que quería bolver a la Reducción, pero que no podía entonces: que iría con toda su gente después. Apretávale el Padre Pedro que la salida avía de ser en aquella ocasión, y no en otra; pero viendo que en tras de una hora de razones el Indio se ponía más terco cuanto más se le persuadía, mudo de estilo el Padre Pedro, y llamando a su gente mandó que amarrasen, y pusiesen un par de grillos a aquel Indio. No dexó de hazerIcaco la resistencia que pudo, pero viéndose que iva de vencida, y que no podía evitar el verse preso, prorrumpió en llanto, y pidió al Padre perdón, y misericordia, prometiendo le seguiría dondequiera que quisiese. Ya no quería el Padre Pedro otra cosa que llevarle preso, porque temía eran fingidos ademanes los del Indio para escaparse a su salvo, pero rogaron tanto los Indios de la Reducción al Padre Pedro para que no lo prendiese, porque dezían que viéndose preso moriría antes emperrado que se reconciliase, y que niguno [sic] de los demás avía de querer salir viendo llevar atado a su Capitán; que condescendió el Padre en fiarse de su palabra, y dexarle suelto. Dióle por cárcel la casa del Palomar, y guardó inviolablemente su prisión, dando claros indicios desde entonces de su arrepentimiento; y que niguna [sic] cosa dezeava más que persuadir a toda su gente que quisiesen irse con él, y con el Padre a la Reducción como con todas las razones que pudo lo procuró, pero ya que no quisieron reducirse todos, no dexaron de seguir cinco o seis familias con los cuales, y con Icaco, bolvió el Padre Artiguez a la Reducción.//

Después de algunos meses pareció conveniente bolver a Miguel Icaco el bastón de Capitán porque avía dado bastantes pruevas de su enmienda, y era necesario embiarlo al Palomar para traer a los indios que habían quedado. A esa diligencia ha ido dos veces en este año, y siempre ha traído alguna gente, que todos al parecer están contentos, y firmes en la Reducción.

Por el mes de Mayo de este año hizo el Padre Pedro Juan Andreu su entrada al Chaco en compañya del Padre Juan de Arizaga. Salieron de esta reducción hasta 40 personas en que ivan 30 Indios flecheros por el riesgo del enemigo, y seis peones ladinos para la cavallada, cargas, y reses que de todo fue bastante prevención por lo que podía ser necesario.

Desde el camino se adelantaron exploradores para los Isistines, y Omoampas; y porque los que fueron a estos estuvieron de buelta en la Puerta, paso del río Salado, antes que los que fueron a los Isistines, se trató de entrar primero a los Omoampas.

42 Traxeronnotitia [sic] los exploradores que los indios se juntarían todos en Macolí, si huviese agua en aquel pozo, de que darían aviso con humos, y aguardarían ahí a los Padres para tomar resolución de lo que se huviese de executar; pero si en Macolí no hubiese agua, saldrían todos a la Petaca a encontrarse con los Padres, de que avisarían también los humos. Nada de eso cumplieron los Omoampas, pues que ni para el día señalado, ni para antes, ni después, asomó humo en parte alguna de aquellas tierras. 
destruida por las guerras que tuvo en años pasados con la de los Lules, quienes, en las últimas refriegas que tuvieron, cogieron varias piezas Omoampas, y se las traxeron a la Reducción, y de estas avía tres mugeres casadas ya con Lules, cuya buena índole, e inclinaciones davan señas de ser los Omoampas mejor gente que los Lules. Avíalo observado el Padre Pedro Andreu poco después de llegado a esta Reducción, cuando el año de 38 llegó a ella un mozo del Tucumán mercader de cera, que contantando [sic] sucesos de las naciones que avía tierra adentro, donde solía entrar a comprar cera, alabó grandemente la nación de los Omoampas, su fidelidad, y legalidad en los tratos, la seguridad con que estavan todas sus cosas entre ellos, y sobre todo la buena disposición, y dezeos que manifestavan de ser Cristianos. Con esa notitia [sic], y aquella observación, concibió el Padre Pedro esperanzas de reducir a esos Indios, y escrivió luego al Padre Provincial Jayme Aguilar pidiendo licencia para esta Misión. Expiró el gobierno del Padre Jayme antes que diese la respuesta, y aunque el Padre Provincial Sebastián de San Martín al pasar por el Tucumán dio facultad para que el Padre Andreu emprendiese esa Misión, nada se executó hasta que visitando la primera vez esta reducción el Padre Provincial Antonio Machoni dispuso que el Padre Pedro Juan Andreu entrase a esa nación en compañya del Padre Joachin de Yegros. Hízose esa primera entrada por Santiago, y Matara, camino larguísimo, y penosysimo por los montes y atravesías. Fueron los Misioneros recibidos de los Omoampas con demonstraciones de alegría, y entendido el fin de la entrada a sus tierras, respondió por todos el Cazique en lengua quichoa: que estaban promptos, y muy gustosos de ser cristianos, pero que no querían ser doctrinados en otra parte sino en sus mismas tierras.

Esa razón se dio al Padre Provincial y en la visita del año siguiente ordenó// su Reverenciaque el Padre Andreu entrase por el Tucumán a hazer una sementera de maíz en las tierras de los Omoampas, e hiziese cavar el pozo manantial de Socolí, paíz proprio [sic] de esa gente, para experimentar si el agua era suficiente, y las tierras a propósito para mantenerse una Reducción. Aunque el Padre Andreu se dio la prysa posible no pudo llegar hasta mediado Marzo a los Omoampas, quienes enterados de su venida dixeron al Padre que no tenía que cansarse en cavar el pozo de Socolí, porque avían desamparado ese parage, y no querían bolver más a él, que saldrían a orillas del Salado donde formarían su Reducción y que en cuanto a la sementera era trabajar sin provecho por ser ya pasado su tiempo. Salióse el Misionero dexando agasajados, y contentos a los Indios y confirmados en el dezeo de hazerse cristianos, y dio cuenta de esos sucesos al Padre Provincial, quien embió al Padre Joachin de Yegros para que fuese a escoger parage a propósito sobre el río Salado donde se pudiese hazer la fundación. 

Misioneros, pero por ser el rigor del ivierno [sic] le faltaron de todo punto las cavalgaduras, y no pudo llegar a ver la Pampa de Don Juan, que según dezían tenía todas las conveniencias para una Reducción. Viose obligado a salir el Padre Joachin sin traer razón del intento, informó al Padre Provincial que estava ya en las Misiones, y aunque su Reverencia dio prompta providencia, se pasó casi un año antes que el Padre Joachin pudiese bolver a registrar los parages. Vista la Pampa de Don Juan parecióle al Padre Joachin al propósito para el intento, dio cuenta al Sup[erior], y como todos los antecedentes conspiravan a la fundación sin que se pudiese rastrear recelo de novedad, subió el Padre Provincial a la Ciudad de Santiago para dar principio por si proprio [sic] a esa Misión, dexándola entablada en el parage de Don Juan. Pero, porque ocurrieron dilaciones en abrir caminos, y otros justos estorbos que no podían superarse en breve, hubo de retirarse su Reverencia a Córdova, dexando las providencias convenientes para que los Padres Joachin de Yegros, y Juan de Arizaga entrasen a hazer esa fundación.

En medio de esas dilaciones que no pudieron evitarse ni evadirse tuvo// tiempo el infierno de hazer guerra y contrastar [a esos] miserables Indios. De una parte los cereadores [sic], que jusgavan ruina de sus ganancias la conversión de los Omoampas; de otra unos Lules apóstatas que huyeron de los castigos que por sus maldades merecían en la Reducción, y guiados del demonio fueron a incorporarse con los Omoampas, supieron persuadir de modo a esos miserables incautos, y disuadirles el que se fuesen a la dirección de los Padres; que quando el Padre Joachin de Yegrosdexó el parage de Don Juan embió a llamarlos para principiar el pueblo, respondieron que no querían ir. Viéndose obligado el Padre Joachin a ir personalmente a buscarles en los montes, y con agasajos, y persuasión y solo pudo sacar de ellos por última resolución que se juntarían en la Petaca y que allí formarían la Reducción pero que a niguna [sic] otra parte querían salir.

Bien conocía el Padre Joachin que la Petaca no era parage a propósito para subsistir mucho tiempo, por ser expuesto a las incursiones del enemigo, y por las angosturas de montes incómodos para un pueblo. Pero con la confianza que los Indios hechos a nuestro trato, y a las conveniencias que en nuestra Compañya experimentarían a pocos meses mudarían parecer, y nos seguirían donde quiera que quisiésemos, se retiró dando cuenta al Padre Provincial de esa novedad, y para que no hubiese medio que no se intentase para ganar a esas almas, ordenó el Padre Provincial que entrase el Padre Joachin a empezar esa Doctrina en la Petaca, y que el Padre Andreu fuese a ayudar con los Lules, para hazer allí una sementera de maíz.

Entró antes el Padre Andreu, y halló en la Petaca toda la nación de los Omoampas junta esperando con ansia al Padre Joachin para entregarse a su dirección. Apenas se acabó la sementera, quando llegó notitia [sic] que el Padre Joachin se avía buelto del camino por estar invadido de enemigos, notitia [sic] que recibieron los Omoampas con imponderable desconsuelo dándose por burlados, y expresando que los Padres les traían engañados con palabras avía tres, o quatro años. $\mathrm{Y}$ aunque al principio desfogaron sus sentimientos diciendo que ya no querían Padres, y que dixesen al Padre Joachin que no bolviese más a sus tierras; pero recibidos algunos donecillos del Padre Pedro, dixeron al despedirse encargase al Padre Joachin viniese quanto antes, que de allí no avían de moverse hasta que llegase.//

51 A pocos meses [descub]rieron los Indios Tobas esa sementera de maíz, y la arruinaron, y derrotaron la ranchería de los Omoampas con muerte de ocho Indios los principales de la nación. 
Ese suceso manifestó no aver seguridad para fundación en aquellas tierras, y que si los Omoampas no querían salir de ellas, no querían su remedio. Pero la ruina padecida fundava esperanzas de que querrían salir del riesgo en que, en cualquiera parte de sus tierras, estavan. Más la innata tenacidad de las mugeres viejas en mantenerse en su paíznativo desvaneció esas esperanzas, y arredró a muchos de los Omoampas que estavan dispuestos, y dezeosos de salir.

Salió el Padre Andreu de los Omoampas, porque entró con poca prevención por la incertidumbre del agua en Macolí, y entró el Padre Juan de Arizaga, y mientras ese Misionero hazía la causa de Dios solicitando diesen esos Indios su última resolución, se encaminó el Padre Andreu a los Isistines. Estaba ya en su mayor fuerza el invierno, los campos sin pastos, los pozos sin agua, la nación muy dividida, por lo que solo pudo ver este Misionero dos parcialidades de ella, y de ahí entresacó veinte almas que quisieron seguirle dexando a los demás contentos con algunos donecillos, y apalabrados para tratar de su salida en otra ocasión mientras rumiavan, y digerían las notitias [sic] que se les dio de Dios, y de las consequencias que de morir cristianos, o infieles podían esperar, o temer.

Juntáronse en la Puerta los dos Misioneros, y de ahí dieron la buelta a Tucumán con los trabajos que Dios sabe porque se remató, y perdió casi toda la cavallada, y lo más de la gente llegó a pie.

Este año ha avido buena salud en la Reducción beneficio de Dios tanto más conocido quantoestava la peste arruinando los partidos circunvezinos. Y quando los curas immediatos no tenían descanso enterrando difuntos, no huvo en la Reducción en todo el año más que un entierro de una muger adulta. Párvulos sí han muerto muchos ahogados de la flemosidad de las aguas sin otro accidente. Daño a que se procura ocurrir con mudar el Pueblo a otra parte sobre que se está trabajando.

También ha mirado Dios con piedad este año a esta reducción librando// sus campos, y sementeras del daño de la langosta que no ha llegado a ella, aviendo esa plaga asolado todo el resto de la jurisdicción.

7 Lo espiritual se promueve lo mejor que se puede, se hacen las fiestas con la solemnidad posible a la pobreza de esta Reducción. Los sábados acude mucha gente a la Misa cantada, y Rosario, pero no toda. En las Fiestas principales hay muchas comuniones pero no todos se juzgan todavía dignos de comulgar.

58 La brutalidad nativa no está en todos totalmente desbastada, ni olvidadas del todo algunas costumbres brutales que tuvieron en los montes. Una muger de las venidas del Palomar parió dos hijos. Avisado del parto el uno de los Padres, fue luego a bautizar la criatura, ignorando huviesen nacido dos. La parida según la antigua costumbre de los montes avía enterrado ia [sic] una o tapado con tierra, y vasura. Bautizó el Padre la criatura que le pusieron delante, y sin más inquirir se bolvía, quando oye gritos en casa de la parida. Eran las mugeresvezinas más antiguas en la Reducción que sabiendo avían nacido dos criaturas, y visto que solo una se había bautizado, afeaban a la parida el hurto de la otra, y decían que aquel era un gran pecado. Entendiólo el Padre, y acudió promptamente mandando buscasen con diligencia la criatura o la sacasen de donde estaba enterrada. Descubrió la parida su culpa, y el lugar, y apartando la vasura, y tierra se reconoció estar viva todavía la criatura. Bautizóla el Padre con nombre de Buenaventura, y la tiene tan buena en vivir que se cría sana, y robusta, quando la primera que se bautizó murió de allí a pocos días. 
Lo temporal de la Reducción se ha mejorado este año con el molino que se ha puesto, y con la donación que ha hecho a la Compañía para esta Reducción el General Don Luis Joseph Dias Teniente de Gobernador de la Ciudad de San Fernando de Catamarca, y la Rioja, de la mitad del Pueblo de Guazan que lo fue de Indios en el Valle de Andargala [sic] con todas las sobras de agua que tiene en aquella su posesión, y del Potrero de las Minas, uno de dos que tiene contiguos aquella Finca. Tierras muy a propósito para trigales, algodonales, viñas, y qualesquiera// árboles frutales, o huertas, y muy cómodos para la Reducción por la immediación en que están del Potrero de Anconquija [sic].

\section{Fuentes}

Archivo General de Indias, Fondo documental de la Audiencia de Charcas, Sección VGobierno, Legajo Charcas 384.

Archivo Histórico S.I. Catalunya, legajo Misiones del Chaco argentino (AC/MI 02).

Biblioteca Nacional de Río de Janeiro, Sección de Manuscritos, Colección De Angelis, rollo 33.

\section{BIBLIOGRAPHY}

Aguilar, N. E. (2016). Los lules del Pasaje Balbuena. La frontera chaqueña occidental (siglos XVII y XVIII). Rosario: Prohistoria Ediciones.

Boccara, G. (1998). Guerre et Ethnogenèse mapuche dans le Chili colonial. L'Invention du soi. París: L'Harmattan.

Citro, S. (2009). Los indígenas chaqueños en la mirada de los jesuitas germanos. Idealización y disciplinamiento de los cuerpos, Anthropos, (104), 399--421.

Calavia Sáez, O. (2013). Nomes, pronomes e categorias: repensando os "subgrupos" numa etnología pós-social, Antropologia em primeira mão, (138), 5-17.

Enrique, L. A. (2018). Huellas del paisaje colonial en las narrativas fundacionales sobre la frontera sur. Buenos Aires: Sociedad Argentina de Antropología.

Farberman, J. y Taboada, C. (2017). ¿ “Lules nómades” y “lules sedentarios”? Sociedades indígenas, movilidad y prácticas de subsistencia en el Salado Medio (Santiago del Estero) En XVI Jornadas Interescuelas. Departamentos de Historia. Mar del Plata.

Furlong, G. S. J. (1941). Entre los lules de Tucumán. Buenos Aires: Talleres gráficos San Pablo.

Giudicelli, C. (2010). Hétéronomie et classifications coloniales. La construction des 'nations' indiennes aux confins de l'Amérique espagnole (XVI-XVIIe siècle), Nuevo Mundo Mundos Nuevos [En Línea], Debates. Disponible en: http://nuevomundo.revues.org/59411.

Justo, M. de la S. (2013). “Que no es todo para todos”. El deber de escribir en la Compañía de Jesús, Actas y comunicaciones del Instituto de Historia antigua y medieval, (9). Disponible en: 
http://www.filo.uba.ar/contenidos/investigacion/institutos/historiaantiguaymedieval/volumen \%209/Portada9.htm

Lucaioli, C. P. (2011). Abipones en las fronteras del Chaco. Una etnografía histórica sobre el siglo XVIII. Buenos Aires: Sociedad Argentina de Antropología.

Maeder, E. (1997). Fuentes jesuíticas de información demográfica misional para los siglos XVII y XVIII. En Celton, D. (Coord.), Fuentes útiles para los estudios de la población americana, (pp. 43-57). Quito: Abya-Yala.

Nacuzzi, L. R. (1998). Identidades impuestas. Tehuelches, aucas y pampas en el norte de la Patagonia. Buenos Aires: Sociedad Argentina de Antropología.

Nacuzzi, L. R. (2002). Leyendo entre líneas: una eterna duda acerca de las certezas. En Visacovsky, S. y Guber, R. (Comps.). Historia y Estilos de Trabajo de Campo en la Argentina, (pp. 229-262). Buenos Aires: Antropofagia.

Nacuzzi, L. R. y Lucaioli, C. P. (2008). “y sobre las armas se concertaron las paces”: explorando las rutinas de los acuerdos diplomáticos coloniales, Revista Cultura-Hombre-Sociedad (CUHSO), 15 (2), 61-74.

Nacuzzi, L. R. y Lucaioli, C. P. (2017). Una reflexión sobre los rótulos históricos y la dificultad de nombrar a los grupos étnicos de Pampa-Patagonia y el Chaco. Nuevo Mundo Mundos Nuevos [En Línea], Debates. Disponible en: http://journals.openedition.org/nuevomundo/71684.

Noli, E. S. (1998). Algarrobo, maíz y vacas. Los pueblos indios de San Miguel del Tucumán y la introducción de ganados europeos (1600-1630). Mundo de Antes, (1), 31-67.

Page, C. (2012). Las otras reducciones jesuíticas. Emplazamiento territorial, desarrollo urbano y arquitectónico entre los Siglos XVII y XVIII. Madrid: Editorial Académica Española.

Palermo, M. A. (2000). A través de la frontera. Economía y sociedad indígenas desde el tiempo colonial hasta el siglo XIX. En Tandeter, E. (Dir.), Nueva Historia Argentina. La sociedad colonial, (pp. 345-382). Buenos Aires: Sudamericana.

Paz, C. (2005). El nudo gordiano de las políticas indígenas de los grupos chaqueños. Misiones, misioneros y guerras en la génesis de una sociedad de jefatura, segunda mitad del siglo XVIII, Revista Historia UNISINOS, 9 (1), 35-48.

Revel, J. (Comp.). (2015). Juegos de escalas: experiencias de microanálisis. San Martín: Universidad Nacional de San Martín.

Rodrigues, J. H. (1951). Explicação. En J. Cortesão, Jesuítas e bandeirantes no Guairá. Manuscritos da Coleção De Angelis, tomo I, (pp. 5-9). Río de Janeiro: Biblioteca Nacional.

Roulet, F. (1999-2001). De cautivos a aliados: los "Indios Fronterizos" de Mendoza (1780-1806). Xama, (14-14), 199-239.

Saeger, J. (2000). The Chaco Mission Frontier. The Guaycuruan Experience. Tucson: The University of Arizona Press.

Santamaría, D. (1994). Del tabaco al incienso. Reducción y conversión en las misiones jesuitas de las selvas sudamericanas. Siglos XVII y XVIII. Jujuy: CEIC.

Scala, M. J. (2015). La reducción jesuítica de San Javier de indios mocoví: historia y relaciones interétnicas en las fronteras del Chaco austral en el siglo XVIII. Tesis de Licenciatura en Ciencias Antropológicas. Universidad de Buenos Aires, Facultad de Filosofía y Letras. Ms.

Tanodi, B. M. (2000). Documentos históricos. Normas de transcripción y publicación. Cuadernos de Historia, Serie Ec. y Soc., Nº 3, Arch. Y Ftes. Córdoba: CIFFyH-UNC, 259-270. 
Vega, F. (2017). Corrección y reescritura jesuíticas en el siglo XVIII: en torno a la obra de José Cardiel (1747-1780), IHS. Antiguos jesuitas en Iberoamérica, V (1), 84-110.

Vitar, B. (1988). Tucumán y el Chaco en el siglo XVIII: milicias, jesuitas y frontera. Madrid: Universidad Complutense de Madrid. Tesis doctoral.

Vitar, B. (1997). Guerra y misiones en la frontera Chaqueña del Tucumán (1700-1767). Madrid: CSIC, Biblioteca de la historia de América.

Vitar, B. (1999). Prácticas abortivas entre las indígenas chaqueñas en el siglo XVIII, Etnohistoria. Publicación especial en CD.

Vitar, B. (2001a). La evangelización del Chaco y el combate jesuítico contra el demonio, Andes, (12), 201-221.

Vitar, B. (2001b). Las mujeres chaqueñas en las reducciones fronterizas del Tucumán: entre la tradición y el cambio (siglo XVIII), Anuario IEHS, (16), 223-244.

Vitar, B. (2003). Algunas notas sobre las figuras de los líderes chaqueños en las postrimerías del siglo XVIII. En Mandrini, R. y Paz, C. (Comps.), Las fronteras hispanocriollas del mundo indígena latinoamericano en los siglos XVI-XIX, (pp. 407-428). Tandil: CEHiR-UNS-Instituto de Estudios Histórico Sociales.

Vitar, B. (2015). La subversión del orden jesuítico: las ancianas indígenas y su resistencia a la acción misionera en el Chaco, Missoes - Revista de Ciencias Humanas e Sociais, I (1), 58-72. Disponible en:

http://publicase.unipampa.edu.br/index.php/missoes/article/view/8610

Wilde, G. (Coord.) (2011). Saberes de la conversión. Jesuitas, indígenas e imperios coloniales en las fronteras de la cristiandad. Buenos Aires: SB.

\section{ABSTRACTS}

In this paper we present the transcription of "Annua histórica de la misión de San Estevan de los indios Lules de 1744", written by the Jesuit missionary Pedro Juan Andreu. This manuscript belongs to the unpublished De Angelis Collection, which is preserved in the Biblioteca Nacional de Río de Janeiro (BNRJ). The account informs about the material state of the reduction of San Esteban in Western Chaco and the results of two specific tasks requested by the Jesuit Province authorities. It focuses on the description of three indigenous groups --lules, isistines and omoampas-- from a historical perspective. The document also contains hints we consider relevant to study the interethnic relations in the frontiers of the Chaco region during colonial times. In the preliminary study presented along with this transcription, we first contextualize the manuscript as a historically situated document. Secondly, we identify and examine some of the main data that contributes to the history of the indigenous groups of Chaco in particular and to the frontier studies in general.

En este trabajo presentamos la transcripción de un documento escrito por el cura doctrinero Pedro Juan Andreu, titulado “Anua histórica de la Misión de San Estevan de los Indios Lules de 1744". El manuscrito forma parte de la inédita Colección De Angelis, adquirida y preservada por la Biblioteca Nacional de Río de Janeiro. El relato apunta a informar sobre el estado de la reducción y sobre los resultados de dos tareas específicas relativas al control de grupos indígenas insumisos, asignadas por el padre provincial en su visita anual. Para abordar estos temas, se incluyen datos sobre otras cuestiones relevantes para el estudio de la coyuntura interétnica del 
período colonial desde una perspectiva que reconoce la historicidad de los grupos étnicos del Chaco occidental. El comentario crítico que acompaña esta transcripción se organiza siguiendo dos ejes principales: el primero orientado a situar el documento en sus diversos contextos; el segundo apunta a identificar y deslindar los datos del discurso que nos permitan avanzar en el análisis de distintas problemáticas de la historia indígena en particular y de los estudios de frontera en general.

\section{INDEX}

Keywords: Jesuits, indigenous groups, Chaco, interethnic relations, frontiers

Palabras claves: Jesuitas, indígenas, Chaco, relaciones interétnicas, fronteras

\section{AUTHORS}

\section{CARINA P. LUCAIOLI}

Centro de Investigaciones Sociales - Consejo Nacional de Investigaciones Científicas y Técnicas/ Instituto de Desarrollo Económico y Social (CONICET/IDES), Argentina

Correo electrónico: carinalucaioli@gmail.com

\section{DANIELA SOSNOWSKI}

Centro de Investigaciones Sociales - Consejo Nacional de Investigaciones Científicas y Técnicas/ Instituto de Desarrollo Económico y Social (CONICET/IDES), Argentina Correo electrónico: dani.sos@gmail.com 